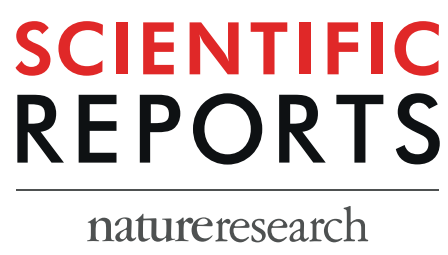

There are amendments to this paper

\title{
Life cycle assessment of maize cultivation and biomass utilization in northern Thailand
}

\begin{abstract}
Titaporn Supasri ${ }^{1,3}$, Norihiro Itsubo ${ }^{4}$, Shabbir H. Gheewala ${ }^{5,6}$ \& Sate Sampattagu| $\left.\right|^{2,3^{*}}$
Maize, a major food source for the world, is a high-yield commodity crop, and one of five major crops in Thailand. Occupying about 33\% of the Thai upland farmlands, maize farming has been growing tremendously especially in northern Thailand. However, after harvesting, open burning is widely used in order to get rid of maize cobs and husks in land preparation for the next period. The current maize farming practices have caused several problems to local communities as well as urban dwellers. The objectives of this research were: (i) to analyze the life cycle inventory of maize cultivation, maize cob pellet production and heavy fuel oil production in northern Thailand using IDEA v2.0 and ecoinvent v3.0 databases; (ii) to evaluate environmental impacts of maize cultivation, maize cob pellet production and heavy fuel oil production using A Global Scale Environmental Life Cycle Impact Assessment (LIME3 ) with the results of weighting (Country-specific) based on monetary valuation of end-points. This study evaluated the life cycle environmental impacts of maize cultivation and continuing through biomass energy production from maize cob by comparing with heat production from heavy fuel oil in Mae Chaem and Chiang Dao districts in the north of Thailand by using two different databases, IDEA v2.0 and ecoinvent v3.0 with an endpoint-based life cycle impact assessment (LCIA) method (LIME-3). The system boundary of this study includes land preparation, planting, weeding, farming, harvesting, maize cob pellet production and heat production from maize cob pellet and heavy fuel oil. The units of analysis in this study are $1 \mathrm{~kg}$ of maize grain, $3.76 \mathrm{E}-03 \mathrm{MJ}$ of biomass energy production from maize cob and 3.76E-03 MJ of heat production from heavy fuel oil, respectively. The data were obtained from field survey supplemented with the Thai National Life Cycle Inventory Database and other scientific publications. The results included the environmental impacts of maize cultivation and continuing through biomass energy production from maize cob by comparing with heat production from heavy fuel oil in Mae Chaem and Chiang Dao districts by using two different databases with LCIA method on the endpoint approaches (LIME-3). The total damage cost based on IDEA v2.0 life cycle inventory (LCI) database in Mae Chaem and Chiang Dao districts was about 4.64E-01 USD and 4.89E-01 USD, respectively. As regards ecoinvent v3.0 database, the total damage cost in Mae Chaem and Chiang Dao districts was about 5.37E-01USD and 5.99E-01 USD, respectively. It can be seen that the total damage cost using different inventory databases in Chiang Dao are slightly higher than Mae Chaem due to different input materials. The result of total cost using inventory data from ecoinvent v3.0 is slightly higher than IDEA v2.0 due to different inventory processes in each database. However, the results in this study demonstrated that the databases show similar trends in the assessment results. On the other hand, certain numerical differences between the databases at some points were found to be more substantial. The results of present study are particularly relevant to policy choices for improving or using the good practices for maize cultivation, which would reduce the environmental performance of maize production systems in the area. To address the air pollution issue from biomass open burning of
\end{abstract}

${ }^{1}$ Energy Engineering Program, Faculty of Engineering, Chiang Mai University, Chiang Mai, Thailand. ${ }^{2}$ Department of Industrial Engineering, Faculty of Engineering, Chiang Mai University, Chiang Mai, Thailand. ${ }^{3}$ Center of Excellence on Energy, Economic, and Ecological Management (3E), Science and Technology Research Institute, Chiang Mai University, Chiang Mai, 50200, Thailand. 'Faculty of Environmental and Information Studies, Tokyo City University, 3-3-1 Ushikubonishi, Tsuzuki, Yokohama, Kanagawa, 224-8551, Japan. ${ }^{5}$ The Joint Graduate School of Energy and Environment (JGSEE), King Mongkut's University of Technology Thonburi, Bangkok, Thailand. ${ }^{6}$ Center of Excellence on Energy Technology and Environment, PERDO, Ministry of Higher Education, Science, Research and Innovation, Bangkok, Thailand. *email: sate@eng.cmu.ac.th 


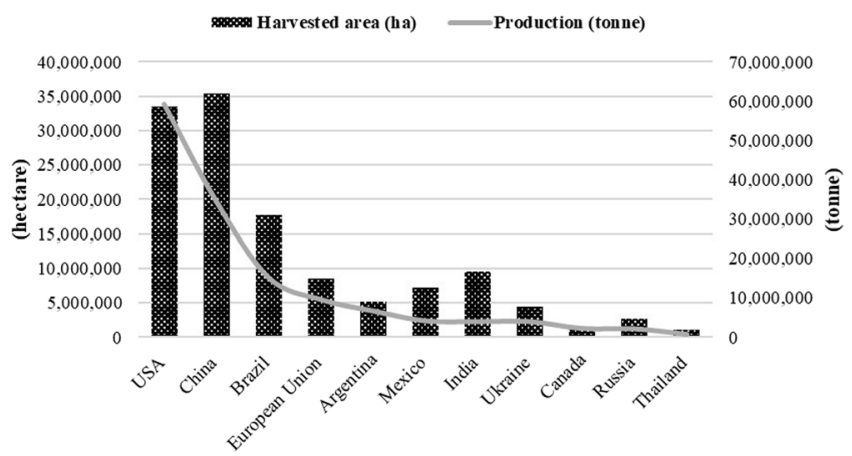

Figure 1. The harvested area, production and yield per hectare of maize from major countries in 2017.

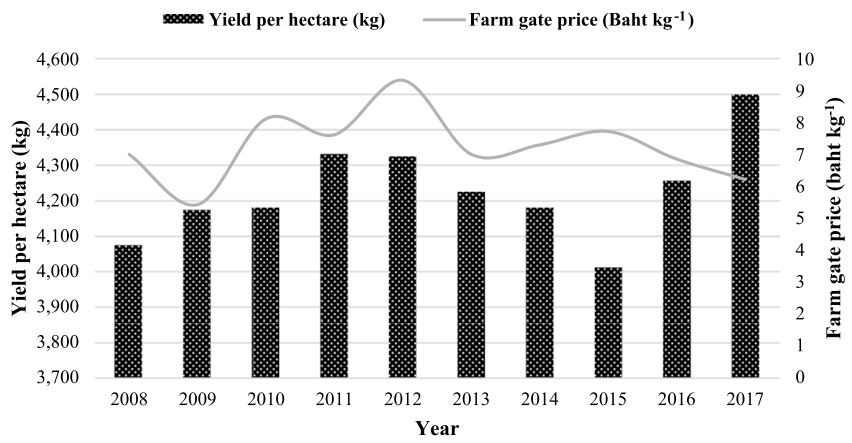

Figure 2. Yield per hectare and farm gate price of maize in Thailand.

agricultural residues in the study area, the government agencies in Thailand should be responsible for promoting better biomass management for the future.

Maize (Zea mays L.), a high-yield commodity crop, is a major food source for the world. In 2017, the harvested area of maize in the world was 7,209 million hectares, which decreased by $0.51 \%$ from 7,246 million hectares in crop year 2016.

Maize production was 6,527 million tonnes, which decreased by $2.87 \%$ from 6,720 million tonnes in the same period. In addition, maize yield was $5,656 \mathrm{~kg} / \mathrm{ha}$, which decreased by $2.37 \%$ from $5,794 \mathrm{~kg} / \mathrm{ha}$. USA had the highest maize production, followed by China and Brazil, respectively. Overall, maize production in most countries decreased while that in Argentina, Canada and Thailand was increasing. The harvested area, production and yield per hectare of maize from major producing countries in 2017 are shown in Fig. 1.

Maize is one of five major crops in Thailand in addition to rice, cassava, sugarcane, and rubber. It occupies a major portion (about 33\%) of the Thai upland farmlands ${ }^{1}$. In 2017, the maize production in Thailand was 41 million tonnes, which increased from year 2016 by $1.26 \%$. Maize production was 29 million tonnes, which increased by $7.06 \%$ from 27 million tonnes. Moreover, maize yield was $4,500 \mathrm{~kg} / \mathrm{ha}$, which increased by $5.73 \%$ from 4,256 kg/ha since it was supported by the Promotion on Dry Season Maize Production after Major Rice Crop Year 2017 Project. Moreover, maize yield increased because the amount of rainfall was enough for growth (rainy season) $)^{2}$.

Demand of maize for Thailand in 2017 was 8 million tonnes, which increased by $3.58 \%$ from 7 million tonnes in 2016. Because of the expansion of the livestock industry, demand for maize in animal feed increased. Thailand exported 0.32 million tonne of maize with a total value 72.55 million USD, which decreased from 0.6 million tonne with total value was 151.23 million USD in 2016. Maize exports and value decreased by $44.83 \%$ and $52.03 \%$, respectively because of the increase in domestic demand of maize. As a result, maize exports were decreasing to partner countries such as the Philippines, Vietnam and China ${ }^{2}$. Figure 2 shows the yield per hectare and farm gate price of Thailand between 2008-2017.

In Thailand, the current maize farming practices have also caused several problems to local communities as well as urban dwellers. For example, the widespread forestland clearing has led to flooding and landslides, resulting in road accidents and crop damage. In addition, the excessive use of chemical fertilizers and pesticides has caused environmental impacts and burning crop residues after harvesting, leading to air pollution and haze which affect human health.

There are many different ways to produce biomass energy including biomass burning to generate heat in thermal systems. To compare environmental impacts of biomass energy use to continued fossil fuel use, replacing fossil fuels such as heat production from petroleum fuels with biomass energy can reduce $\mathrm{CO}_{2}$ emissions and avoided biomass burning after harvesting process. Therefore, it is necessary for the full utilization of biomass in 
order to manage the amount of biomass after harvesting and avoid biomass burning, as well as reduce the environmental impacts.

This study was conducted using the Life Cycle Assessment (LCA) methodology. LCA is a quantitative procedure to evaluate the environmental impacts within the set system boundary. Many researchers are using LCA derived information to drive business and policy decisions. The guiding principles of LCA follow the International Organization for Standardization (ISO) standards ISO $14040^{3}$ and ISO $14044^{4}$. These two ISO standards provide an overview of the steps of LCA: (1) Goal and scope definition; (2) life-cycle inventory analysis (LCI); (3) life-cycle impact assessment (LCIA); and (4) interpretation.

The objectives of this research were as follows: (i) to analyze the life cycle inventory of maize cultivation continuing through biomass energy production from maize cob by comparing with heat production from heavy fuel oil in northern Thailand using the IDEA v2.0 and ecoinvent v3.0 databases; and (ii) to evaluate environmental impacts of maize cultivation, maize cob pellet production and heat production from heavy fuel oil using LIME-3 with the results of weighting (Country-specific) based on monetary valuation of end-points.

\section{Literature Review}

The literature review revealed that many researchers have reported the benefits of applying the LCA approach in terms of environmental management of agricultural production systems. Many studies have been conducted on environmental impacts assessment focused on maize production and biomass utilization activities. A previous study by Kim et al. ${ }^{5}$ estimated the environmental impacts for the cultivation of corn grain and corn stover in the US Corn Belt and predicted that removing corn stover from soil could reduce nitrogen emissions from soil. In 2014, Wang et al. ${ }^{6}$ examined the environmental impacts of the wheat-maize rotation system between conventional farming system and double high system in Quzhou. Boone et al. ${ }^{7}$ assessed the environmental footprint of grain maize production using the ReCiPe and CEENE methods. Recently, Fantin et al. ${ }^{8}$ assessed the environmental impacts of wheat and maize production in Italy using the ILCD approach. The major hotspot for both crops in the agricultural phase was due to fertilizers and pesticides used. Moreover, Holka et al. ${ }^{9}$ accessed two large-scale farms in the Wielkopolska region, west-central Poland during 2011-2013. The study found that the stages of crop cultivation and harvesting produced the biggest impact on acidification, eutrophication and global warming. The largest source of environmental burdens came from fertilization. Moreover, the normalized values of impact indicators showing that lifecycle environmental burdens of grain maize production were mainly associated with soil acidification. Jason et al. ${ }^{10}$ estimated GHG emissions of maize production in the US. The total climate change damage was about US $\$ 4.9$ billion or $15 \mathrm{USD} \mathrm{t}^{-1}$ of maize. Also, the average health damages from air pollution were equal to $121 \mathrm{USD} \mathrm{t}^{-1}$ of harvested maize grain.

There are many impact studies focusing on biomass utilization from agricultural residues, Nilsson et al. ${ }^{11}$ analyzed the costs and energy requirements for biomass pellet production in Sweden. Song et al. ${ }^{12}$ evaluated the environmental impacts and economic value of corn straw pellet fuel in Jilin Province, China. In Thailand, open burning of agricultural residues could be avoided and the unburned residue could also substitute fossil energy. Suramaythangkoor and Gheewala ${ }^{13}$ evaluated the potential for heat and power generation from the rice straw that would otherwise be open burnt in Thailand. Kerdsuwan and Laohalidanond ${ }^{14}$ analyzed the economic aspects using corn residue for alternative energy source in order to produce power in Nakorn Sawan and Petchchaboon provinces. In the case of northern Thailand, there is a large amount of corn production as well. Therefore, Phonin et al..$^{15}$ found the best clusters with minimum transportation cost for several constraints set for corn product/ waste management system in northern area of Thailand using models and simulation in order to assess the total $\mathrm{CO}_{2}$ emissions from the waste elimination process, open burning and transforming to biomass pellet plant. Recently, Yodkhum et al. ${ }^{16}$ assessed the environmental burdens of GHG emissions, energy use, and particulate matter formation $\left(\mathrm{PM}_{10}\right)$, from rice cultivation in Chiang Mai province, northern Thailand and compared the environmental burdens of rice straw utilization scenarios such as, open burning, incorporation into soil, and direct combustion for electricity generation.

In recent years, several life-cycle impact assessment (LCIA) studies have been published. For example, Itsubo and Inaba ${ }^{17}$ developed a Japanese LCIA methodology based on endpoint modeling (LIME). Then, Itsubo et al..$^{18}$ developed weighting factors relevant to the Group of Twenty (G20) countries also compared the weighting factors calculated for individual countries. In addition, Yamaguchi et al. ${ }^{19}$ developed an LCIA method focused on the biodiversity in land use classification using LIME method. Murakami et al. ${ }^{20}$ estimated the willingness to pay and annual global damage cost on monetary weighting factors (MWFs) for the G20 countries. Inaba and Itsubo ${ }^{21}$ have developed LIME-3 in Japan using the monetary valuation method to authorize the global scale environmental impacts assessment. In order to assess the human health damage, Tang et al. ${ }^{22}$ calculated human health damage factors based on the Special Report on Emission Scenarios (SRESs) consisting of malaria, diarrhea, cardiovascular disease, malnutrition, coastal flooding, and inland flooding developed by IPCC. The results showed that the damage caused by malnutrition was the greatest, followed by diarrhea. Moreover, Tang et al. ${ }^{23}$ estimated the human health damage factors of $\mathrm{PM}_{2.5}$ which initiating from ten different regions of the world by using a global chemical transport model.

The present study aims at addressing the differences between the IDEA v2.0 and ecoinvent v3.0 databases using LIME- 3 to analyze the environmental impact with the results of weighting (Country-specific) based on monetary valuation of endpoints. Comparison between the two databases based on the normalization results of the selected pilot study of substitution by biomass energy is conducted. The environmental impact of maize cultivation and maize cob pellet production by comparing with heat production from heavy fuel oil in northern area Thailand is then analyzed using both databases. The difference between the databases results is investigated and suggestions provided. Based on these results, suggestions on when to adopt an endpoint approach and how to interpret the different results from the two databases are provided. Finally, the limitations and recommendations of the database and approaches are discussed. 


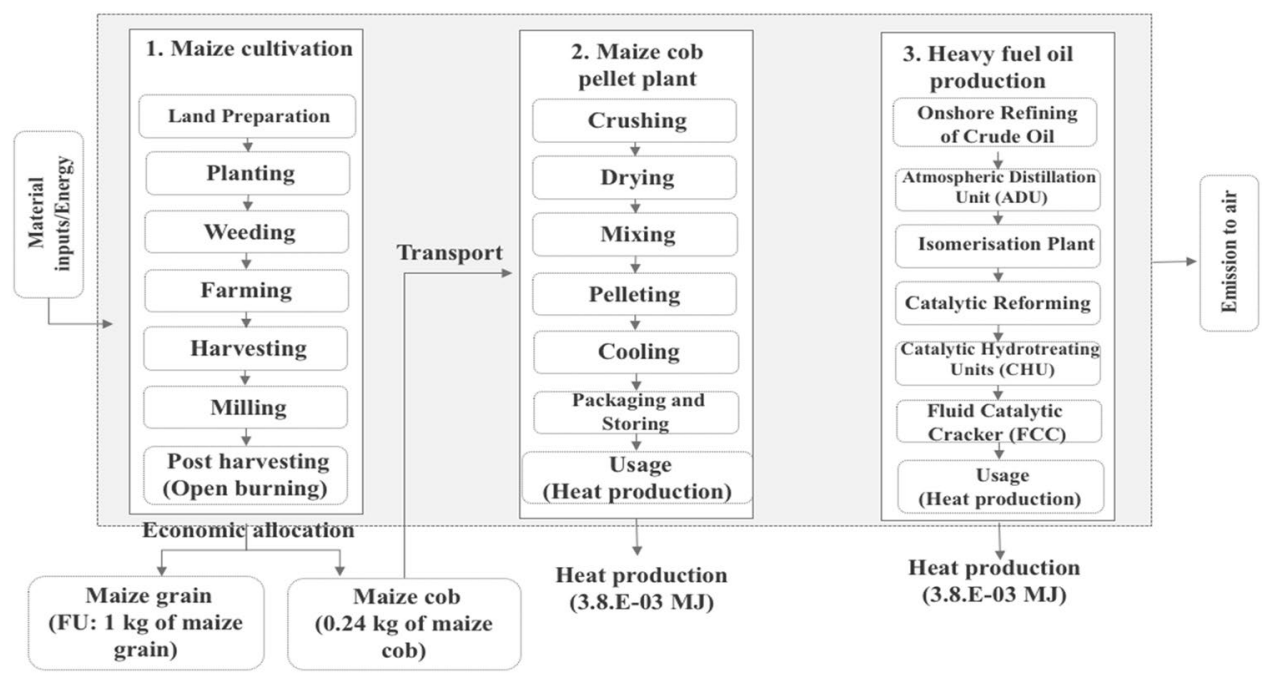

Figure 3. System boundary.

\section{Objectives}

This study aims to analyze the life cycle inventory of maize cultivation, maize cob pellet production by comparing with heat production from heavy fuel oil in northern Thailand using IDEA v2.0 and ecoinvent v3.0 databases, as well as to evaluate environmental impacts of maize cultivation, maize cob pellet production and heat production from heavy fuel oil using LIME-3.

\section{Methodology}

Goal and scope of this study. The goal of this study was to provide an assessment of maize cultivation, maize cob pellet production by comparing with heavy fuel oil production based on the LCA methodology. The system boundary (cradle to gate) starts from land preparation and continues through planting, weeding, and farming processes, followed by the harvesting and milling processes and post-harvesting (open burning). After the post-harvesting process, the maize cob is transported to the pellet plant for producing maize cob pellet. Moreover, this study calculated the emissions reduction by comparing with the heavy crude oil refining until the heat production from heavy oil. Economic allocation was applied to the maize grain and maize cob production, which is being sold on the market for livestock and energy applications. Maize grain and maize cob impacts were allocated using economic allocation factors according to the average market prices referring to the Office of Agricultural Economics ${ }^{2}$, resulting in $92 \%$ for maize grain and $8 \%$ for maize cob. The units of analysis in this study are $1 \mathrm{~kg}$ of maize grain and 3.76E-03 MJ of biomass energy production from maize cob and 3.76E-03 MJ heat production from heavy fuel oil, respectively. Figure 3 shows the system boundary of this study.

Focus area. In northern Thailand, the maize area cultivated amounted to 28 million ha in 2016 with approximately, 19 million tonnes of maize grain being produce. Mae Chaem district is one of the most cultivated areas in northern region of Chiang Mai province with a cultivation area under maize of approximately 12,307 ha in 2015 while Chiang Dao district was about 5,305 $\mathrm{ha}^{2}$. The present study thus focuses on the important areas producing a large amount of maize in Chiang Mai, Thailand, such as, Mae Chaem and Chiang Dao districts.

The first study area, Mae Chaem, is located in the west of Chiang Mai province, in northern Thailand. Latitude and longitude of Mae Chaem coordinates are $18^{\circ} 29^{\prime} 56^{\prime \prime} \mathrm{N} 98^{\circ} 21^{\prime} 43^{\prime \prime} \mathrm{E}$ covering an area of 2,733.26 $\mathrm{km}^{2}$. Most of the terrain in the Mae Chaem district is covered by forest and upland areas. Steep mountains, piedmont alluvial plains, and plain areas make up the district at about 70\%, 20\%, and $10 \%$ of the total area. Forests cover about $82.08 \%$ of the total area in Mae Chaem. The next largest land use is agriculture at $16.92 \%$ of the total area. The second area, Chiang Dao, is a district located in the north of Chiang Mai. Geographically, it lies at the $19^{\circ} 21^{\prime} 58^{\prime \prime} \mathrm{N}$ $98^{\circ} 57^{\prime} 51^{\prime \prime} \mathrm{E}$ and covers an area of $1,882.1 \mathrm{~km}^{2}$. Most of the terrain in Chiang Dao district is covered by upland areas as well. Figure 4 shows agricultural land use map of Mae Chaem and Chiang Dao districts.

According to the $\mathrm{OAE}^{2}$, maize production in Chiang Mai in 2015 was about 603,344 tonnes; the maize residues (cobs, leaves, and stalks) were about 1,254,955 tonnes; and the maize production in Mae Chaem district was about 338,600 tonnes. The average yield per hectare was 4,400 kg while the maize residues were about 704,288 tonnes. In Chiang Dao district, maize production was about 111,906 tonnes and the average yield per hectare was $3,420 \mathrm{~kg}$ while the maize residues were about 232,765 tonnes. Maize farming in northern Thailand is growing tremendously. However, after harvesting processes, open burning is widely used in order to get rid of maize cobs and husks in land preparation for next period. The statistical data of planted area, harvested area, and yield per hectare of the two study areas in 2012-2015 are shown in Fig. 5.

In northern Thailand, the first crop of maize is usually grown in May. After the first rain, land preparation and sowing are started in April-May. Land preparation consists of land clearing, burning maize residue, and tillage. Land clearing and maize residues burning are often done from February to March, and tillage is mostly done in April before sowing, which is 2-7 days later; farmers start sowing the maize seeds, and they use organic fertilizers in order to accelerate the growth of maize. After 30 days, the farmers spray the weeds with herbicides. In the next 

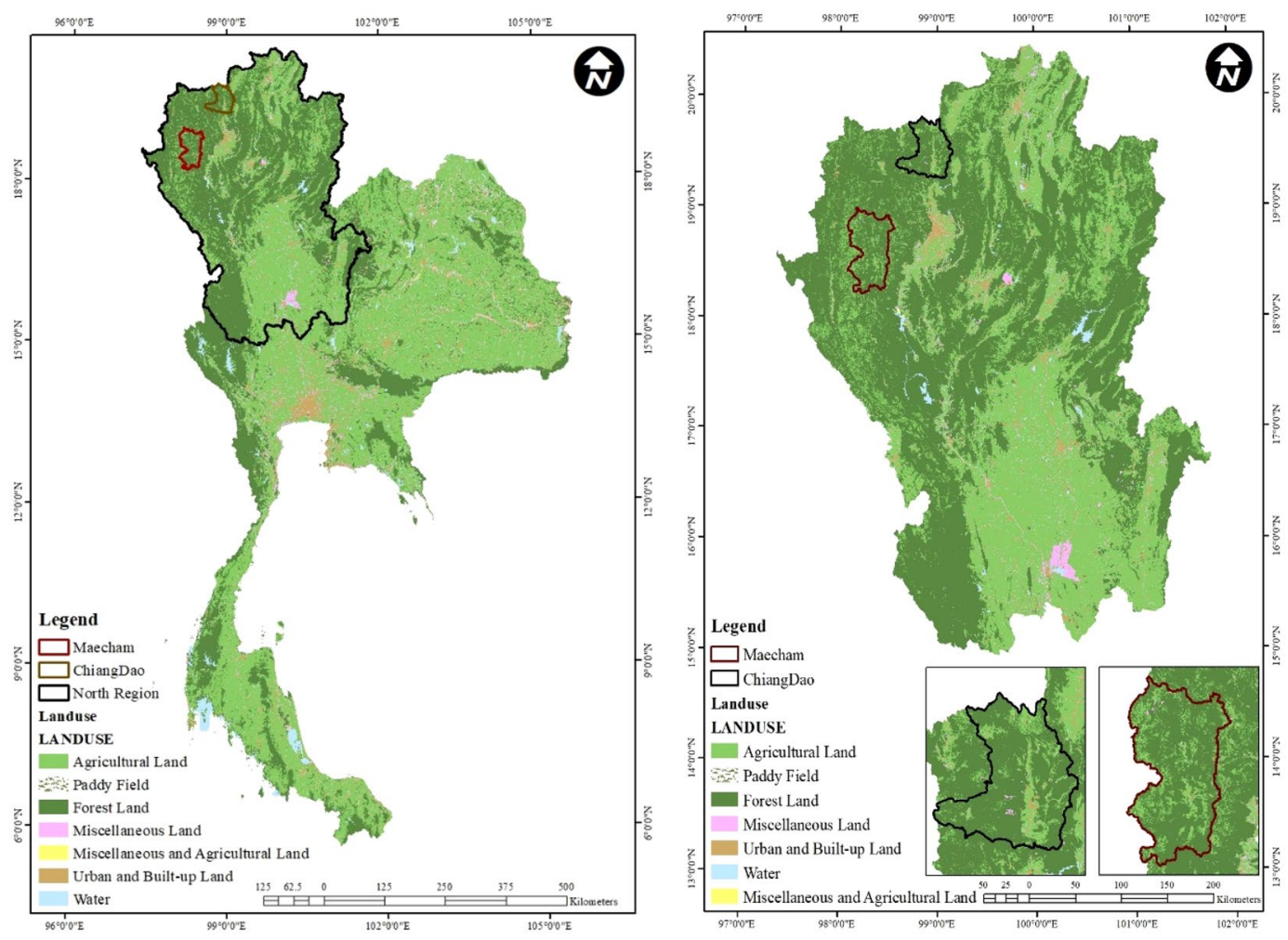

Figure 4. Agricultural land use map of Mae Chaem and Chiang Dao districts, northern Thailand.

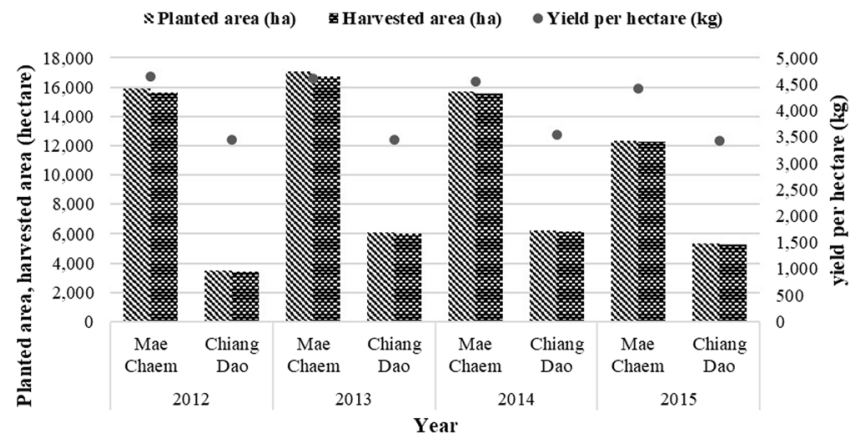

Figure 5. Maize: planted area, harvested area and yield per hectare of study area (2012-2015).

30 days, they use chemical fertilizers. The overall plantation period is 110 days. Finally, the farmers harvest their product and dry it in the field in either November or December. The farmers were observed when milling the dry maize using diesel machines. As maize residues are only partially utilized, nowadays, in the northern region, most of the maize residues (cobs, leaves, and stalks) are disposed of by open burning because it is the fastest and the most inexpensive way and it saves cost as regards to harvesting and land preparation.

Thailand has a biomass energy potential including biomass residues which can be used to produce heat energy for development of alternative energy all over the country. Especially, the north of Thailand produces a large amount of maize. According to the Department of Alternative Energy Development and Efficiency ${ }^{24}$, the physical properties of maize cobs consist of moisture content of $20-27 \%$, ash content of $8 \%$ and a calorific value of 15.68 $\mathrm{MJ} / \mathrm{kg}$. The market price of maize pellets is about 3,000-4,000 baht/tonne (about 100-130 USD/tonne). Maize cob pellets are used in small-scale boilers for domestic thermal production that can replace conventional oil (heavy fuel oil) or gas boilers for industries that require large amounts of heat such as, tobacco curing plants, dried longan factory and maize grain drying. Generally, the processes of maize cob pellet production in Thailand are quite simple with very few stages which are crushing of raw material, drying, pelletizing, cooling, and packaging and storing ${ }^{25}$.

Data collection and inventory data. The primary data in this study were obtained directly by face-to-face questionnaires in totally 100 rai (16 hectare) of maize production area in the study areas in 2016 . The data include 


\begin{tabular}{|c|c|c|c|c|}
\hline Focus area & Maize production Stage & Input & Quantity & Unit \\
\hline \multirow{10}{*}{ Mae Chaem } & Land preparation & - & - & - \\
\hline & \multirow{3}{*}{ Planting } & Maize seed & 18.75 & $\mathrm{~kg} \mathrm{ha}^{-1}$ \\
\hline & & Organic fertilizer & 1,250 & $\mathrm{~kg} \mathrm{ha}^{-1}$ \\
\hline & & NPK (15:15:15) Fertilizer & 312.50 & $\mathrm{~kg} \mathrm{ha}^{-1}$ \\
\hline & \multirow{2}{*}{ Weeding } & Atrazine & 2.19 & $\mathrm{~kg} \mathrm{ha}^{-1}$ \\
\hline & & Alachlor & 3.13 & $\mathrm{~kg} \mathrm{ha}^{-1}$ \\
\hline & \multirow{2}{*}{ Farming } & NPK (15:15:15) Fertilizer & 93.75 & $\mathrm{~kg} \mathrm{ha}^{-1}$ \\
\hline & & Urea $(46-0-0)$ & 312.50 & $\mathrm{~kg} \mathrm{ha}^{-1}$ \\
\hline & Harvesting and Milling & Diesel & 6.25 & $\mathrm{~L} \mathrm{ha}^{-1}$ \\
\hline & Post harvesting (Open burning) & Diesel & 3.13 & $\mathrm{Lha}^{-1}$ \\
\hline \multirow{9}{*}{ Chiang Dao } & Land preparation & Diesel & 18.75 & $\mathrm{~L} \mathrm{ha}^{-1}$ \\
\hline & \multirow{2}{*}{ Planting } & Maize seed & 18.75 & $\mathrm{~kg} \mathrm{ha}^{-1}$ \\
\hline & & Diesel & 18.75 & $\mathrm{~L} \mathrm{ha}^{-1}$ \\
\hline & Weeding & Paraquat dichloride & 25 & $\mathrm{~L} \mathrm{ha}^{-1}$ \\
\hline & \multirow{2}{*}{ Farming } & Urea $(46-0-0)$ & 312.50 & $\mathrm{~kg} \mathrm{ha}^{-1}$ \\
\hline & & Paraquat dichloride & 12.50 & $\mathrm{~kg} \mathrm{ha}^{-1}$ \\
\hline & \multirow{2}{*}{ Harvesting and Milling } & Diesel & 62.50 & $\mathrm{Lha}^{-1}$ \\
\hline & & Fertilizer bag & 62.50 & $\mathrm{~kg} \mathrm{ha}^{-1}$ \\
\hline & Post harvesting (Open burning) & Diesel & 6.25 & $\mathrm{~L} \mathrm{ha}^{-1}$ \\
\hline
\end{tabular}

Table 1. Inputs of the various stages in maize production.

\begin{tabular}{|c|c|c|c|}
\hline Focus area & Output & Quantity & Unit \\
\hline \multirow{9}{*}{ Mae Chaem } & \multicolumn{3}{|l|}{ Main product } \\
\hline & Maize yield & 4,400 & $\mathrm{~kg} \mathrm{ha}^{-1}$ \\
\hline & \multicolumn{3}{|l|}{ Co-product } \\
\hline & Maize residue (leaves, and stalks) & 8,119 & $\mathrm{~kg} \mathrm{ha}^{-1}$ \\
\hline & Maize residue (cob) & 1,059 & $\mathrm{~kg} \mathrm{ha}^{-1}$ \\
\hline & \multicolumn{3}{|l|}{ Emissions } \\
\hline & \multicolumn{3}{|l|}{ Airborne emissions from diesel ${ }^{28}$} \\
\hline & \multicolumn{3}{|l|}{ Fertilizers emissions ${ }^{29}$} \\
\hline & \multicolumn{3}{|l|}{ Herbicides emissions (air and soil) ${ }^{29}$} \\
\hline \multirow{9}{*}{ Chiang Dao } & \multicolumn{3}{|l|}{ Main product } \\
\hline & Maize yield & 3,419 & $\mathrm{~kg} \mathrm{ha}^{-1}$ \\
\hline & \multicolumn{3}{|l|}{ Co-product } \\
\hline & Maize residue (leaves, and stalks) & 6,288 & $\mathrm{~kg} \mathrm{ha}^{-1}$ \\
\hline & Maize residue (cob) & 820 & $\mathrm{~kg} \mathrm{ha}^{-1}$ \\
\hline & \multicolumn{3}{|l|}{ Emissions } \\
\hline & Airborne emissions from diesel ${ }^{28}$ & & \\
\hline & Fertilizers emissions $^{29}$ & & \\
\hline & Herbicides emissions (air and soil) ${ }^{29}$ & & \\
\hline
\end{tabular}

Table 2. Outputs of the various stages in maize production.

raw materials for maize production such as fertilizers, herbicides, including diesel fuel which is used in agricultural machinery and transportation. The calculations and assumptions are identifiable based on the secondary data in the existing databases in SimaPro, such as IDEA v2.026, ecoinvent v3.0 $0^{27}$, the Thai national database, the EMEP/EEA air pollutant emission inventory ${ }^{28}$ and IPCC $^{29}$ guidelines. For the maize production stage, the inputs include maize seeds, fertilizers, pesticides, diesel, and transportation. The system outputs contain all of the products and co-products as well as pollutants emitted to the environment. The inputs and outputs of the various stages in maize production are shown in Tables 1 and 2.

For the maize cob pellet production stage in this study, the inputs include only electricity consumption for operating the machines. The production output is 1 tonne/hour of maize cob pellet with a net calorific value of about $15.68 \mathrm{MJ} / \mathrm{kg}$. Totally, heat production from this pellet plant is about 15,680 MJ/hour. Table 3 shows the inputs and outputs of maize cob pellet and heat production for 1 tonne/hour. As regards to heavy fuel oil production, the inputs started with the onshore refining of crude oil, Atmospheric Distillation Unit, isomerization plant, catalytic reforming, Catalytic Hydro treating Units, Fluid Catalytic Cracker and heat production from heavy fuel oil. 


\begin{tabular}{|l|l|l|l|}
\hline Maize cob pellet production Stage & Input & Quantity & Unit \\
\hline Crushing & Electricity & 2.2 & $\mathrm{kWh} / \mathrm{t}$ \\
\hline Drying & Electricity & 7.5 & $\mathrm{kWh} / \mathrm{t}$ \\
\hline Pelleting & Electricity & 2.2 & $\mathrm{kWh} / \mathrm{t}$ \\
\hline Cooling & Electricity & 1.1 & $\mathrm{kWh} / \mathrm{t}$ \\
\hline Packaging and Storing & Electricity & 2.2 & $\mathrm{kWh} / \mathrm{t}$ \\
\hline Usage (heat) & $\begin{array}{l}\text { Maize cob } \\
\text { pellet }\end{array}$ & 1 & tonne \\
\hline
\end{tabular}

Table 3. Inputs of maize cob pellet and heat production.

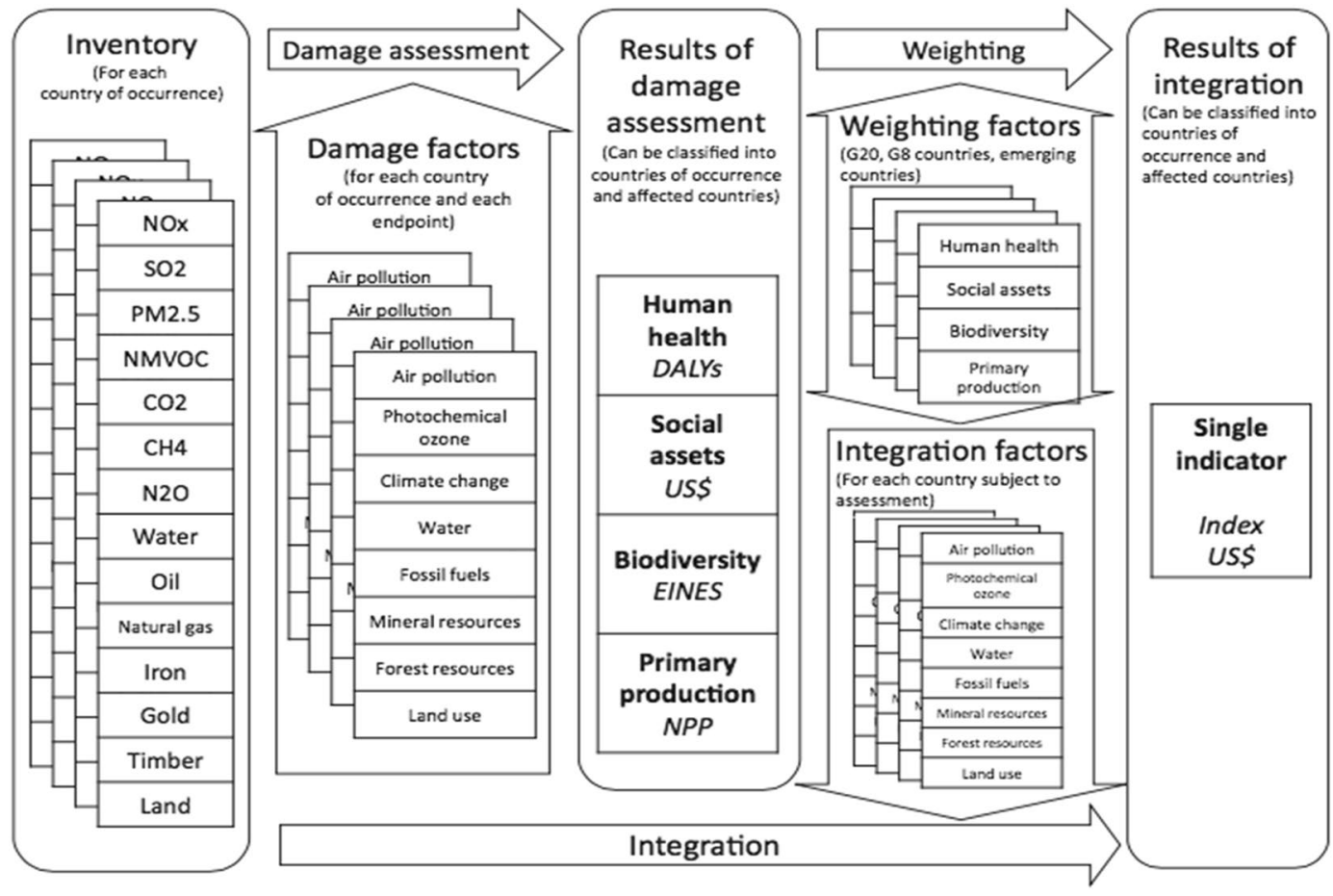

Figure 6. Conceptual figure of LIME-3.

Life cycle impact assessment. LIME-3 was developed in 2016 in order to be used in the entire world. Nine impact categories of characterization which included climate change, air pollution, photochemical oxidants creation, water consumption, land use, mineral resource consumption, fossil fuel consumption, forest resource consumption, and solid waste were analyzed and four endpoints which comprise human health, social assets, biodiversity, and primary production. The aggregate analysis for weighting factors was conducted in all G20 countries. This study used country-specific weighting factors for Thailand to calculate damage cost with interest rate of about $5 \%$ as the results of weighting based on monetary valuation of end-points (USD). The conceptual figure of LIME-3 is shown in Fig. 6.

\section{Results and Discussion}

Results of life cycle inventory analysis. The study collected the LCI data from the IDEA v2.0, ecoinvent v3.0 databases, focusing on the inventory related to impact assessment on climate change, air pollution, photochemical oxidants creation, water consumption, land use, mineral resource consumption, fossil fuel consumption and forest resource consumption such as, $\mathrm{CO}_{2}, \mathrm{SO}_{2}, \mathrm{NO}_{\mathrm{x}}, \mathrm{PM}_{2.5}$, Oil, Coal, Natural gas, Water, Land transformation and Land occupation. The life cycle inventory databases of IDEA v2.0 and ecoinvent v3.0 are shown in Table 4.

The results show the difference in values when using the two LCI databases. The latest versions of the two databases at the time the research was carried out were used. In the IDEA v2.0 database, primary inventory data are estimated based on each statistical classification to assure high exhaustiveness and detailed inventory data of various products, and activities are calculated in more detailed classification classes from literature, theoretical figures and process data of factory. However, this database covers only Japanese industrial activities. It is necessary to collect inventory data of foreign countries and to consider with imported products. On the other hand, the ecoinvent database comprises of the LCI data covering all economic activities which describes an activity 


\begin{tabular}{|c|c|c|c|c|c|c|c|c|c|}
\hline \multicolumn{10}{|l|}{ IDEA v2.0 database } \\
\hline \multirow[b]{2}{*}{ Inventory } & \multirow[b]{2}{*}{ Unit } & \multicolumn{2}{|c|}{$\begin{array}{l}\text { LCI of maize cultivation (FU: } 1 \mathrm{~kg} \\
\text { of maize grain) (1) }\end{array}$} & \multicolumn{2}{|c|}{$\begin{array}{l}\text { LCI of maize cob pellet } \\
\text { production including heat } \\
\text { production (FU: } 3.76 \mathrm{E}-03 \mathrm{MJ} \text { of } \\
\text { heat production) (2) }\end{array}$} & \multicolumn{2}{|c|}{$\begin{array}{l}\text { LCI of heavy fuel oil including } \\
\text { heat production (FU: } 3.76 \mathrm{E}-03 \\
\text { MJ of heat production) (3) }\end{array}$} & \multicolumn{2}{|c|}{ Total LCI $(4)=(1)+(2)-(3)$} \\
\hline & & Mae Chaem & \begin{tabular}{|l|} 
Chiang Dao \\
\end{tabular} & Mae Chaem & Chiang Dao & Mae Chaem & Chiang Dao & Mae Chaem & Chiang Dao \\
\hline $\mathrm{CO}_{2}$ & $\mathrm{~kg}$ & $2.27 \mathrm{E}-01$ & $2.93 \mathrm{E}-01$ & 7.16E-05 & 7.16E-05 & 3.02E-04 & 3.02E-04 & $2.27 \mathrm{E}-01$ & $2.92 \mathrm{E}-01$ \\
\hline $\mathrm{SO}_{2}$ & $\mathrm{~kg}$ & 2.77E-04 & 2.36E-04 & 2.93E-08 & 2.93E-08 & 2.51E-07 & 2.51E-07 & 2.77E-04 & $2.35 \mathrm{E}-04$ \\
\hline $\mathrm{NO}_{\mathrm{x}}$ & $\mathrm{kg}$ & 3.71E-03 & $4.54 \mathrm{E}-03$ & 3.52E-08 & 3.52E-08 & $1.57 \mathrm{E}-07$ & 1.57E-07 & 3.71E-03 & $4.54 \mathrm{E}-03$ \\
\hline $\mathrm{PM}_{2.5}$ & $\mathrm{~kg}$ & 1.15E-02 & $1.18 \mathrm{E}-02$ & $7.24 \mathrm{E}-10$ & $7.24 \mathrm{E}-10$ & $1.11 \mathrm{E}-08$ & $1.11 \mathrm{E}-08$ & $1.15 \mathrm{E}-02$ & $1.18 \mathrm{E}-02$ \\
\hline Oil & $\mathrm{kg}$ & $2.86 \mathrm{E}-02$ & 6.05E-02 & $1.48 \mathrm{E}-06$ & $1.48 \mathrm{E}-06$ & 9.27E-05 & 9.27E-05 & $2.85 \mathrm{E}-02$ & $6.04 \mathrm{E}-02$ \\
\hline Coal & $\mathrm{kg}$ & $9.23 \mathrm{E}-03$ & 5.75E-03 & 9.66E-06 & 9.66E-06 & \begin{tabular}{|l}
$2.28 \mathrm{E}-09$ \\
\end{tabular} & 2.28E-09 & $9.24 \mathrm{E}-03$ & 5.76E-03 \\
\hline Natural gas & $\mathrm{kg}$ & 5.93E-02 & 6.49E-02 & 1.69E-05 & 1.69E-05 & $1.66 \mathrm{E}-06$ & $1.66 \mathrm{E}-06$ & 5.93E-02 & $6.50 \mathrm{E}-02$ \\
\hline Water & $\mathrm{m}^{3}$ & $2.25 \mathrm{E}-03$ & $1.25 \mathrm{E}-03$ & $4.29 \mathrm{E}-11$ & $4.29 \mathrm{E}-11$ & $1.35 \mathrm{E}-12$ & $1.35 \mathrm{E}-12$ & $2.25 \mathrm{E}-03$ & $1.25 \mathrm{E}-03$ \\
\hline Land transformation & $\mathrm{m}^{2}$ & 8.53E-05 & $1.10 \mathrm{E}-04$ & $2.01 \mathrm{E}-13$ & $2.01 \mathrm{E}-13$ & $2.64 \mathrm{E}-15$ & $2.64 \mathrm{E}-15$ & $8.53 \mathrm{E}-05$ & 1.10E-04 \\
\hline Land occupation & $\mathrm{m}^{2} \mathrm{y}$ & $1.20 \mathrm{E}-03$ & 1.49E-04 & 3.47E-11 & 3.47E-11 & $1.16 \mathrm{E}-12$ & $1.16 \mathrm{E}-12$ & $1.20 \mathrm{E}-03$ & 1.49E-04 \\
\hline \multicolumn{10}{|c|}{ ecoinvent v3.0 database } \\
\hline \multirow[b]{2}{*}{ Inventory } & \multirow[b]{2}{*}{ Unit } & \multicolumn{2}{|c|}{$\begin{array}{l}\text { LCI of maize cultivation (FU: } 1 \mathrm{~kg} \\
\text { of maize grain) (1) }\end{array}$} & \multicolumn{2}{|c|}{$\begin{array}{l}\text { LCI of maize cob pellet } \\
\text { production including heat } \\
\text { production (FU: } 3.76 \mathrm{E}-03 \mathrm{MJ} \text { of } \\
\text { heat production) (2) }\end{array}$} & \multicolumn{2}{|c|}{$\begin{array}{l}\text { LCI of heavy fuel oil including } \\
\text { heat production (FU: } 3.76 \mathrm{E}-03 \\
\text { MJ of heat production) (3) }\end{array}$} & \multicolumn{2}{|c|}{ Total LCI $(4)=(1)+(2)-(3)$} \\
\hline & & Mae Chaem & \begin{tabular}{|l|l} 
Chiang Dao \\
\end{tabular} & Mae Chaem & Chiang Dao & Mae Chaem & Chiang Dao & Mae Chaem & Chiang Dao \\
\hline $\mathrm{CO}_{2}$ & $\mathrm{~kg}$ & $3.38 \mathrm{E}-01$ & 5.47E-01 & $1.02 \mathrm{E}-04$ & $1.02 \mathrm{E}-04$ & $6.95 \mathrm{E}-04$ & $6.94 \mathrm{E}-04$ & 3.37E-01 & $5.47 \mathrm{E}-01$ \\
\hline $\mathrm{SO}_{2}$ & $\mathrm{~kg}$ & 6.72E-04 & $1.32 \mathrm{E}-03$ & 3.10E-08 & 3.10E-08 & 5.33E-06 & 5.33E-06 & 6.67E-04 & $1.32 \mathrm{E}-03$ \\
\hline $\mathrm{NO}_{\mathrm{x}}$ & $\mathrm{kg}$ & 3.83E-03 & $4.78 \mathrm{E}-03$ & 8.04E-08 & 8.04E-08 & $1.22 \mathrm{E}-06$ & $1.21 \mathrm{E}-06$ & $3.83 \mathrm{E}-03$ & $4.78 \mathrm{E}-03$ \\
\hline $\mathrm{PM}_{2.5}$ & $\mathrm{~kg}$ & $1.15 \mathrm{E}-02$ & 1.19E-02 & 3.20E-09 & $3.20 \mathrm{E}-09$ & 3.87E-08 & 3.87E-08 & 1.15E-02 & 1.19E-02 \\
\hline Oil & $\mathrm{kg}$ & 3.39E-02 & 6.81E-02 & \begin{tabular}{|l|}
$3.81 \mathrm{E}-07$ \\
\end{tabular} & 3.81E-07 & $2.18 \mathrm{E}-04$ & $2.18 \mathrm{E}-04$ & 3.37E-02 & 6.79E-02 \\
\hline Coal & $\mathrm{kg}$ & $1.54 \mathrm{E}-02$ & $1.88 \mathrm{E}-02$ & 1.92E-06 & 1.92E-06 & \begin{tabular}{|l|}
$8.66 \mathrm{E}-06$ \\
\end{tabular} & 8.66E-06 & $1.53 \mathrm{E}-02$ & \begin{tabular}{|l|}
$1.88 \mathrm{E}-02$ \\
\end{tabular} \\
\hline Natural gas & $\mathrm{kg}$ & \begin{tabular}{|l|}
$4.86 \mathrm{E}-02$ \\
\end{tabular} & 6.29E-02 & $2.94 \mathrm{E}-06$ & $2.94 \mathrm{E}-06$ & \begin{tabular}{|l|}
$8.16 \mathrm{E}-06$ \\
\end{tabular} & $8.15 \mathrm{E}-06$ & $4.86 \mathrm{E}-02$ & $6.29 \mathrm{E}-02$ \\
\hline Water & $\mathrm{m}^{3}$ & $5.96 \mathrm{E}-11$ & 7.39E-11 & $1.89 \mathrm{E}-15$ & $1.89 \mathrm{E}-15$ & $1.30 \mathrm{E}-14$ & $1.29 \mathrm{E}-14$ & 5.95E-11 & $7.39 \mathrm{E}-11$ \\
\hline Land transformation & $\mathrm{m}^{2}$ & $1.24 \mathrm{E}-02$ & 1.70E-02 & 3.03E-08 & 3.03E-08 & $1.58 \mathrm{E}-08$ & $1.58 \mathrm{E}-08$ & $1.24 \mathrm{E}-02$ & $1.70 \mathrm{E}-02$ \\
\hline Land occupation & $\mathrm{m}^{2} \mathrm{y}$ & 6.87E-03 & $2.54 \mathrm{E}-02$ & 2.85E-08 & 2.85E-08 & $1.36 \mathrm{E}-08$ & 1.36E-08 & 6.87E-03 & $2.54 \mathrm{E}-02$ \\
\hline
\end{tabular}

Table 4. Life cycle inventory database of IDEA v2.0 and ecoinvent v3.0.

at a unit process level. The LCI results of ecoinvent datasets are used for identifying environmentally preferable goods or services. Therefore, the database should be considering the relevance and completeness of the data for the specific assessment. However, the results in this study demonstrated that the databases show similar trends in the assessment results. On the other hand, certain numerical differences between the databases at some points were found to be more substantial.

Results of weighting calculation using the IDEA v2.0 database. The results of the weighting calculation for the main step of maize cultivation phase, maize cob pellet production and heavy fuel oil production are divided in two different areas using the IDEA v2.0 LCI database and presented in Fig. 7 as percentage contributions to the damage cost. In Mae Chaem district, maize cultivation ( $1 \mathrm{~kg}$ of maize grain) produced the biggest damage cost which is approximately $90 \%$ in $\mathrm{PM}_{2.5}$, and the cost is about $4.18 \mathrm{E}-01$ USD. The second damage cost occurred in $\mathrm{NO}_{\mathrm{x}}$ and is about 3.21E-02 USD, or approximately 7\%. The results present the main cause of the contribution which is from the biomass burning in the post harvesting process. As regards to maize cob pellet production (3.76E-03 MJ of heat production), the biggest damage cost occurred in $\mathrm{CO}_{2}$ and is higher than $40 \%$, and the cost is about 1.22E-06 USD, followed by natural gas which is about $6.19 \mathrm{E}-07$ USD or 23\%. Regarding the heavy fuel oil production (3.76E-03 MJ of heat production), the largest damage cost contributed by oil is almost $70 \%$, and the cost is about $1.78 \mathrm{E}-05$ USD followed by $\mathrm{CO}_{2}$ which is about 5.16E-06 USD or 20\%. Finally, the results of total damage cost are the highest in $\mathrm{PM}_{2.5}$ at approximately $90 \%$, followed by $\mathrm{NO}_{\mathrm{x}}$ which is about $7 \%$. The results of Chiang Dao district are similar to those of the Mae Chaem district. The results show that the biggest damage cost in maize cultivation, maize cob pellet production and heavy fuel oil production occurred in $\mathrm{PM}_{2.5}$, $\mathrm{CO}_{2}$ and oil which is about $4.29 \mathrm{E}-01 \mathrm{USD}$ or $88 \%, 1.22 \mathrm{E}-06 \mathrm{USD}$ which is approximately $45 \%$, and $1.78 \mathrm{E}-05 \mathrm{USD}$ which is approximately $70 \%$, respectively.

Regarding the total damage cost based on the IDEA v2.0 LCI database, Mae Chaem and Chiang Dao districts contributed a total damage cost of about 4.64E-01 USD and 4.89E-01 USD, respectively. The main contributions from the maize cultivation are about 4.64E-01 USD and 4.89.E-01 USD, respectively. The hotspot total damage cost is the highest in $\mathrm{PM}_{2.5}$ or approximately $90 \%$, followed by $\mathrm{NO}_{\mathrm{x}}$ which is about $7 \%$ at Mae Chaem district and the total damage cost is the highest in $\mathrm{PM}_{2.5}$ or approximately $88 \%$, followed by $\mathrm{NO}_{\mathrm{x}}$ which is about $8 \%$ in Chiang Dao district. Although the results of the two areas were similar, the total damage cost in Chiang Dao is slightly higher than Mae Chaem, resulting in the total damage costs depending on the various input materials in each process. 


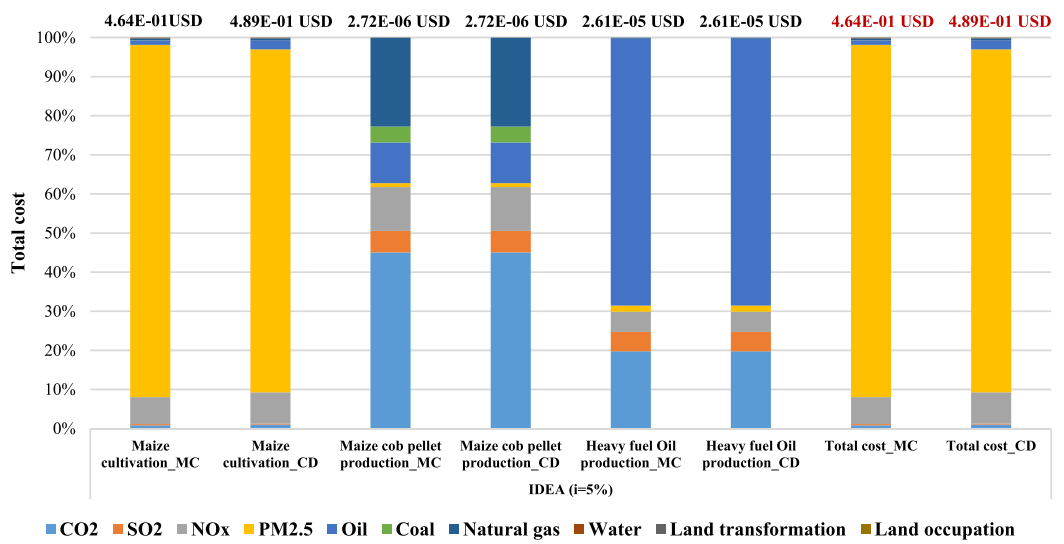

Figure 7. The weighting result of case study using IDEA v2.0 database $(i=5 \%)$.

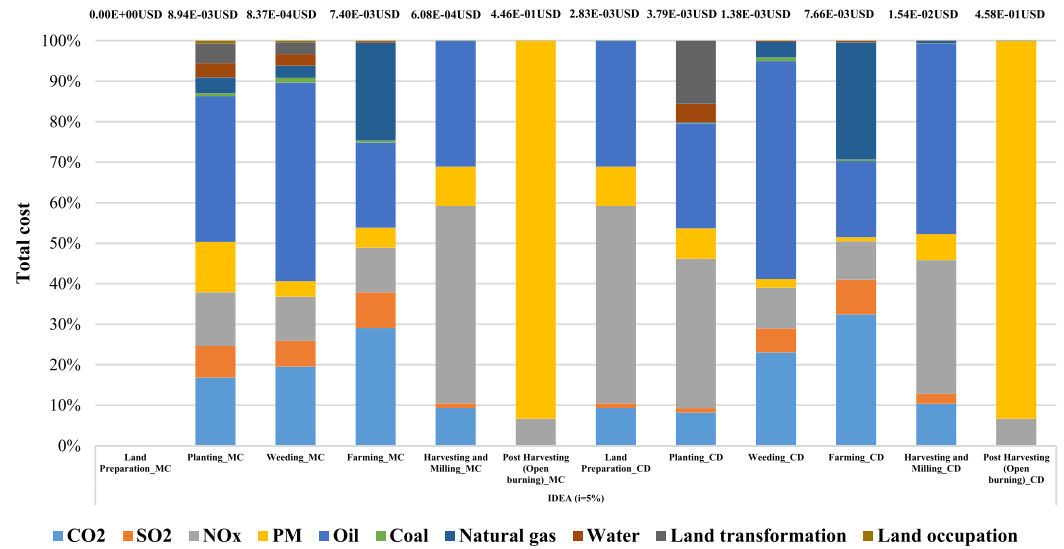

Figure 8. Total damage cost contribution of maize cultivation using IDEA v 2.0 database $(i=5 \%)$.

Regarding the main contribution of total damage cost based on the IDEA v2.0 LCI database, the results present the largest contribution which is from the maize cultivation phase ( $1 \mathrm{~kg}$ of maize grain) occurred in $\mathrm{PM}_{2.5}$ in both areas which is approximately $90 \%$ due to biomass burning in the post harvesting process. The total damage cost of $\mathrm{PM}_{2.5}$ in post harvesting process by biomass burning is about 4.16E-01 USD at Mae Chaem and 4.27E-01 USD at Chiang Dao. Figure 8 shows the total damage cost contribution in maize cultivation using IDEA v2.0 database.

Results of weighting calculation using the ecoinvent v3.0 database. Referring to the results of weighting calculation using the ecoinvent v3.0 LCI database, maize cultivation (1 kg of maize grain) in Mae Chaem produced the biggest damage cost which is almost $80 \%$ in $\mathrm{PM}_{2.5}$, and the costs is about 4.19E-01 USD and the largest damage cost in Chiang Dao also occurred for $\mathrm{PM}_{2.5}$ at approximately $72 \%$, which is about $4.32 \mathrm{E}-01$ USD. The main results of $\mathrm{PM}_{2.5}$ in both areas are from the biomass burning in the post harvesting process. The next contribution is land transformation from the current practice of maize cultivation which would be move to new crop every year. The damage cost of land transformation is 6.7E-02 USD (12\%) and 9.2E-02 USD (15\%) respectively. As regards to maize cob pellet production (3.76E-03 MJ of heat production) in Mae Chaem and Chiang Dao, the highest damage cost contributed is from $\mathrm{CO}_{2}$ which contributes approximately $60 \%$. The cost is about 1.8E-06 USD, followed by $\mathrm{NO}_{\mathrm{x}}$ which is about 7.0E-07 USD (almost 25\%) in both areas. As regards to heavy fuel oil production (3.76E-03 MJ of heat production) in Mae Chaem and Chiang Dao, oil has the highest contribution which is about $4.2 \mathrm{E}-05 \mathrm{USD}(45 \%)$ and the second contribution is $\mathrm{SO}_{2}$ which is about 2.7E-05 USD (approximately $30 \%$ ) in both areas.

Regarding the ecoinvent v3.0 LCI database, the total damage cost of Mae Chaem is about 5.37E-01 USD. The highest damage cost from the maize cultivation is about 5.37E-01 USD. Also, with Chiang Dao district, the highest damage cost from the maize cultivation is about 5.98E-01 USD and the total damage cost is about 5.98E-01 USD. As regards the total damage cost of two areas, $\mathrm{PM}_{2.5}$ has the highest at approximately $78 \%$ and $72 \%$ in Mae Chaem and Chiang Dao, respectively, followed by land transformations which are about $13 \%$ and $15 \%$, respectively. In summary, these results are similar to those using the IDEA database; Chiang Dao district produced a higher damage cost than Mae Chaem district resulting from different input materials.

Overall, the results of total cost using different inventory databases showed that ecoinvent v3.0 is slightly higher than IDEA v2.0 caused by different inventory processes and data collection, as well as the system boundary 


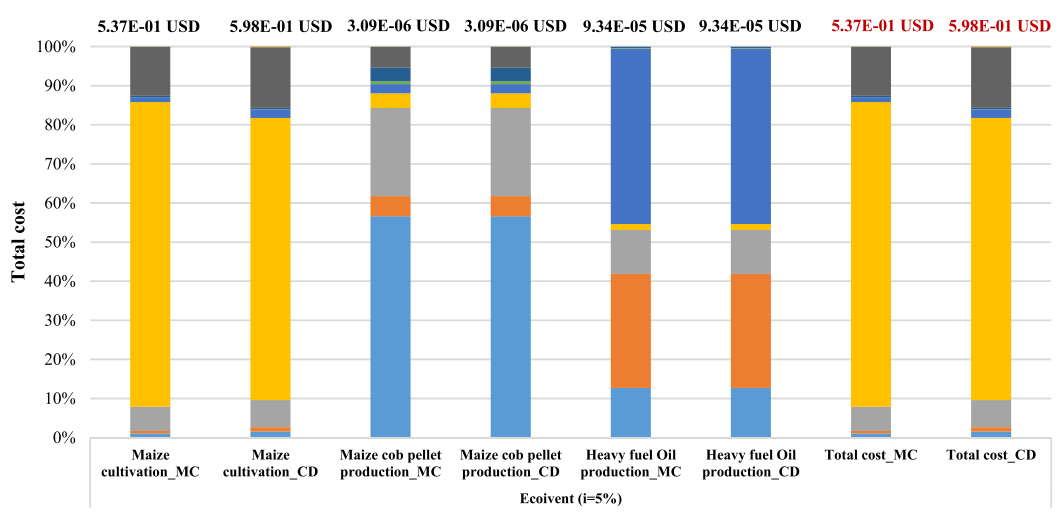

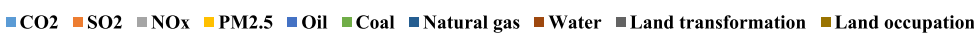

Figure 9. The weighting results of case study using ecoinvent $v 3.0$ database $(i=5 \%)$.

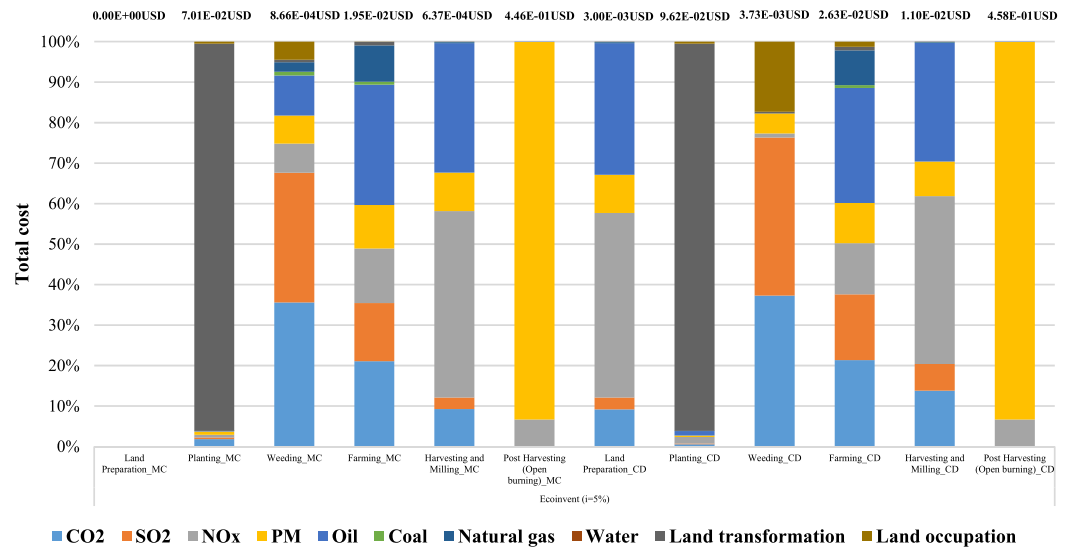

Figure 10. Total damage cost contribution of maize cultivation using ecoinvent $\mathrm{v} 3.0$ database $(\mathrm{i}=5 \%)$.

in each database. Figure 9 shows the percentage contribution to the damage cost for the case study using ecoinvent v3.0 database.

Regarding the main contribution of total damage cost based on the ecoinvent v3.0 LCI database, the results present the largest contribution which is also from the maize cultivation phase ( $1 \mathrm{~kg}$ of maize grain) occurred in $\mathrm{PM}_{2.5}$ in both areas which is approximately between $72-80 \%$ due to biomass burning in the post harvesting process. The total damage cost of $\mathrm{PM}_{2.5}$ in post harvesting process by biomass burning is about $4.16 \mathrm{E}-01 \mathrm{USD}$ at Mae Chaem and 4.27E-01 USD at Chiang Dao. The total damage cost contribution in maize cultivation using the ecoinvent v3.0 LCI database is shown in Fig. 10.

Comparison with other studies. Finally, the results of this study were compared to those obtained from published LCAs on maize cultivation ${ }^{5,69,30}$ since 2009-2017, resulting in GHG emissions of maize cultivation for $1 \mathrm{~kg}$ of maize grain. Nevertheless, all the analyzed studies differ in terms of considered system boundaries, the methodological assumptions, the impact assessment methods and the respective environmental indicators. Therefore, a comprehensive comparison was not always possible although the findings of this study generally correspond to the main outcomes of the other LCAs. As regards to the maize cultivation phase in this study, we assessed the environmental impact for the potential for global warming impact category using LIME-2 ${ }^{17}$ and ReCiPe method ${ }^{31}$ to compare mid-point impact categories of global warming. The highest contribution to global warming impact category occurred in the farming process which is from fertilizer used in both two areas. Moreover, the results of GHG emissions by using ReCiPe method are slightly higher than LIME-2 method (approximately 20-30\%). The results of GHG emissions of maize cultivation for $1 \mathrm{~kg}$ of maize grain are shown in Fig. 11.

As regards to the result of maize cultivation in $1 \mathrm{~kg}$ of maize grain for comparing with other studies, the results of this study per $1 \mathrm{~kg}$ of maize grain gave a total GWP impact of approximately $351.2 \mathrm{~g} \mathrm{CO}_{2}$ eq. This result is presented by box plot to display the five-number summary of a set of data including the minimum, first quartile (25\%), median, third quartile (75\%), and maximum. Figure 12 presents a comparison of the results of maize cultivation in $1 \mathrm{~kg}$ of maize grain with other studies using box plot.

Regarding the environmental impacts of maize production in this study, not only the highest contribution in global warming impact occurred in the farming process from the excessive use of chemical fertilizers and pesticides, there was also an important impact causing air pollution in post harvesting process from the biomass open 


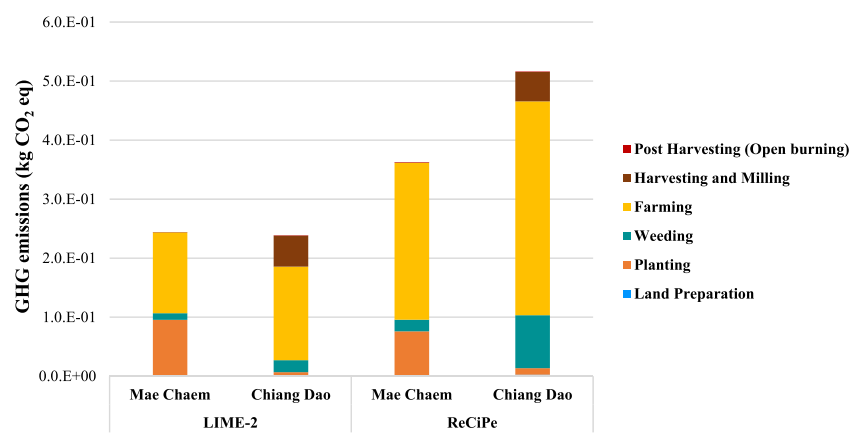

Figure 11. GHG emissions of maize cultivation (1 kg of maize grain).

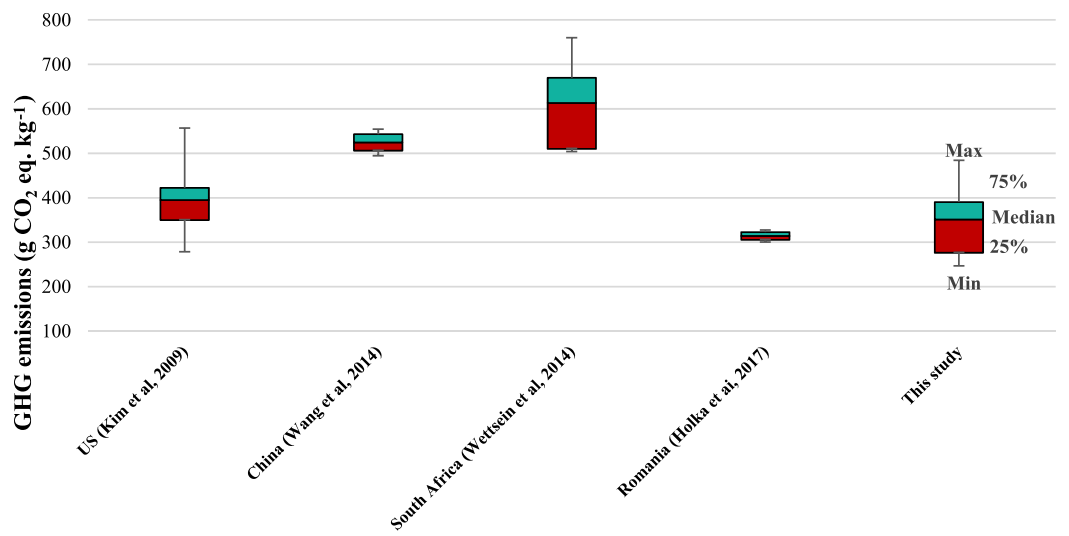

Figure 12. Total GHG emissions of $1 \mathrm{~kg}$ of maize grain compared with other studies.

burning. In order to reduce the environmental problem of maize production systems in the study area, encouraging farmers to plant alternative crops can lead to sustainable agriculture by providing the farmers with alternatives suitable for their area. Avoiding biomass burning after harvesting process, the agricultural residues are processed to pellets (biomass energy production) widely used for direct burning as fuel for industries that require large amounts of heat, such as tobacco curing plants or dried longan factory. Also making organic fertilizer in order to manage agricultural residues should be considered to solve the problem. Furthermore, maize straw incorporation directly into field has been promoted as a source of organic matter and a way to increase soil quality. Therefore, full incorporation of maize residues could significantly improve soil fertility and maintain crop yields, also reducing the GHG emissions for the focus area.

Increasing land transformation due to the shifting cultivation practice has led to the invasion problem of reserved forest areas by encroaching farmers in northern Thailand. In this study, the areas have been facing the problem of air pollution over the past decade, particularly during the dry season from February to May which is the same period of maize cultivation. The mainly burned areas are forest and agricultural areas. Therefore, air pollution issue has to be discussed for the best practice/policy/strategy and action plan to improve the knowledge on maize cultivation and air quality management. In addition, the support for biomass management should be promoted by the government agencies in Thailand.

As regards to the comparison of replacing fossil fuels as heat production system with biomass energy as a case study of biomass pellet, the results presented that biomass fuel can significantly reduce the total GHG emissions. This study assessed the environmental impacts savings that biomass feedstocks which could be used in heat production in the northern, Thailand offer compared to fossil fuels (generally heavy fuel oil). High yielding crops (about 3-4 tonnes/ha) have a high biomass energy from maize cob pellet conversion efficiency to replace current heavy fuel oil consumption. The analysis has resulted in the following issues which are related to the environmental impacts of maize cultivation, such as GHG emissions and air pollution, with a separate policy best practice/ policy/strategy and action plan in order to manage the biomass after harvesting and avoid biomass burning.

\section{Conclusion}

This study presents an LCA study of maize cultivation and continuing through biomass energy production from maize cob by comparing with heat production from heavy fuel oil in northern Thailand using the IDEA v2.0 and ecoinvent v3.0 databases. The results according to the LIME-3 method showed the major hotspots for both areas in the nine impact categories and calculate damage cost with interest rate is about $5 \%$ as the results of weighting based on monetary valuation of end-points (USD). 
Based on the IDEA v2.0 database, the largest contribution for maize cultivation ( $1 \mathrm{~kg}$ of maize grain) for both areas was from $\mathrm{PM}_{2.5}$ at approximately $90 \%$, the next highest being from $\mathrm{NO}_{\mathrm{x}}$ at approximately $7 \%$ which was from the biomass burning in the post harvesting process. Regarding the maize cob pellet production (3.76E- 03 $\mathrm{MJ}$ of heat production), the biggest damage cost in both areas occurred due to $\mathrm{CO}_{2}$ from electricity consumption contributing more than $40 \%$. The largest damage cost of the heavy fuel oil production $(3.76 \mathrm{E}-03 \mathrm{MJ}$ of heat production) was contributed by oil at almost 70\%. Finally, the total damage cost based on IDEA v2.0 LCI database in Mae Chaem and Chiang Dao districts was about 4.64E-01 USD and 4.89E-01 USD, respectively.

As regards ecoinvent v3.0 database, the largest damage cost of the two areas from maize cultivation $(1 \mathrm{~kg}$ of maize grain) was in post harvesting (open burning) with $\mathrm{PM}_{2.5}$ contributing almost $80 \%$. The next damage cost was land transformation at approximately $15 \%$ which from the current practice of maize cultivation would be moved to the new crop every year. The largest hotpot in maize cob pellet production $(3.76 \mathrm{E}-03 \mathrm{MJ}$ of heat production) was from $\mathrm{CO}_{2}$ reaching $60 \%$ mainly from electricity consumption in machines. The biggest contributor of the heavy fuel oil production (3.76E-03 MJ of heat production) which from oil at about $45 \%$. The total damage cost based on ecoinvent v3.0 in Mae Chaem and Chiang Dao districts is about 5.37E-01USD and 5.99E-01 USD, respectively.

Overall results of total damage cost using different inventory database for both system boundaries in Chiang Dao are slightly higher than Mae Chaem due to different input materials. For the result of total cost using different inventory databases, ecoinvent v3.0 is slightly higher than IDEA v2.0 caused by different inventory processes in each database. However, the results in this study demonstrated that the databases show similar trends in the assessment results.

The results of the present study are particularly relevant to support policy choices for improving or using the good practice for maize cultivation in the north of Thailand, which would reduce the environmental problem/GHG emissions and air pollution of maize production systems. The findings could also be used to further enhance the policy/strategy and action plan to improve biomass management in the agricultural area and air quality management in the north of Thailand for maximum efficiency and sustainability in the future.

Received: 6 May 2019; Accepted: 13 February 2020;

Published online: 26 February 2020

\section{References}

1. Ekasingh, B. Maize Supply and Demand in Thailand (2015).

2. OAE, Office of Agricural Economics. agricultural statistics of thailand 2017. (2017).

3. ISO (International Organization for Standardization). Environmental Management Life Cycle Assessment- Principles and Framework. ISO 14040 (2006a).

4. ISO (International Organization for Standardization). Environmental Management Life Cycle Assessment-Requirements and Guidelines. ISO 14044 (2006b).

5. Kim, S., Dale, B. \& Jenkins, R. Life cycle assessment of corn grain and corn stover in the United States. Int. J. Life Cycle Assess. 14(2), 160-174, https://doi.org/10.1007/s11367-008-0054-4 (2009).

6. Wang, C., Li, X., Gong, T. \& Zhang, H. Life cycle assessment of wheat-maize rotation system emphasizing high crop yield and high resource use efficiency in Quzhou County. J. Clean. Prod. 68, 56-63, https://doi.org/10.1016/j.jclepro.2014.01.018 (2014).

7. Boone, L. et al. Environmental life cycle assessment of grain maize production: An analysis of factors causing variability. Sci. Total. Environ. 553, 551-564, https://doi.org/10.1016/j.scitotenv.2016.02.089 (2016).

8. Fantin, V., Righi, S., Rondini, I. \& Masoni, P. Environmental assessment of wheat and maize production in an Italian farmers' cooperative. J. Clean. Prod. 140, 631-643, https://doi.org/10.1016/j.jclepro.2016.06.136 (2017).

9. Holka, M., Bieńkowski, J., Jankowiak, J. \& Dąbrowicz, R. Life cycle assessment of grain maize in intensive, conventional crop production system. Rom. Agric. Res. 2(34), 301-310 (2017).

10. Jason, H. et al. Air-quality-related health damages of maize. Nat. Sustain. 2, 397-403, https://doi.org/10.1038/s41893-019-0261-y (2019).

11. Nilsson, D., Bernesson, S. \& Hansson, P. Pellet production from agricultural raw materials e A systems study. Biomass Bioenerg. 35(1), 679-689, https://doi.org/10.1016/j.biombioe.2010.10.016 (2010).

12. Song, S. et al. Life cycle assessment and economic evaluation of pellet fuel from corn straw in China: A case study in Jilin Province. Energy J. 130, 373-381, https://doi.org/10.1016/j.energy.2017.04.068 (2017).

13. Suramaythangkoor, T. \& Gheewala, H. Implementability of rice straw utilization and greenhouse gas emission reductions for heat and power in Thailand. Waste Biomass Valor 2(2), 133-147, https://doi.org/10.1007/s12649-011-9065-7 (2011).

14. Kerdsuwan, S. \& Laohalidanond, K. Approach of using Corn Residue as Alternative Energy Source for Power Production: A Case Study of the Northern Plain Area of Thailand. Energy Procedia. 79, 125-130, https://doi.org/10.1016/j.egypro.2015.11.495 (2015).

15. Phonin, S., Likasiri, C. \& Dankrakul, S. Clusters with Minimum Transportation Cost to Centers: A Case Study in Corn Production Management. Games. 8(2), 24, https://doi.org/10.3390/g8020024 (2017).

16. Yodkhum, S., Sampattagul, S. \& Gheewala, S. Energy and environmental impact analysis of rice cultivation and straw management in northern Thailand. Env. Sci. Pollut. R. 25, 17654-17664, https://doi.org/10.1007/s11356-018-1961-y (2018).

17. Itsubo, N \& Inaba, A. LIME2 life cycle impact assessment method based on endpoint modeling, LCA newsletter, No. 14, https:// lca-forum.org. Accessed 26 Oct 2018 (2012).

18. Itsubo, N. et al. Int. J. Life Cycle Assess. 23(12), 2311-2326, https://doi.org/10.1007/s11367-015-0881-z (2015).

19. Yamaguchi, K., Ii, R. \& Itsubo, N. Ecosystem damage assessment of land transformation using species loss. Int. J. Life Cycle Assess. 23, 2327-2338, https://doi.org/10.1007/s11367-016-1072-2 (2018).

20. Murakami, K. et al. Development of weighting factors for G20 countries. Part 2: estimation of willingness to pay and annual global damage cost. Int. J. Life Cycle Assess. 23(12), 2349-2364, https://doi.org/10.1007/s11367-017-1372-1 (2018).

21. Inaba, A. \& Itsubo, N. Int. J. Life Cycle Assess. 23, 2271, https://doi.org/10.1007/s11367-018-1545-6 (2018).

22. Tang, L., Ii, R., Tokimatsu, K. \& Itsubo, N. Development of human health damage factors related to $\mathrm{CO}_{2}$ emissions by considering future socioeconomic scenarios. Int J Life Cycle Assess, https://doi.org/10.1007/s11367-015-0965-9 (2018a).

23. Tang, L. et al. Development of human health damage factors for $\mathrm{PM}_{2.5}$ based on a global chemical transport model. Int. Life Cycle Assess. 23(12), 2300-2310, https://doi.org/10.1007/s11367-014-0837-8 (2018b).

24. DEDE, Department of Alternative Energy Development and Efficiency. Biomass Database Potential in Thailand (2012).

25. Thambanchacheep, C. Wood pellet manufacturing in thailand. Dissertation, Shinnawatra University (2006). 
26. Tahara, K. et al. Development of inventory database for environmental analysis(IDEA). Proceedings of the 9th International Conference on Ecobalance. 119, https://doi.org/10.1109/TENCON.2012.6412246 (2010).

27. Ecoinvent. Ecoinvent Database 3.0. Ecoinvent Centre. https://doi.org/10.4018/978-1-59140-342-5.ch003 (2013).

28. EEA, European Environment Agency. EMEP/EEA air pollutant emission inventory guidebook 2013: technical guidance to prepare national emission inventories, Publications Office of the European Union, Luxembourg (2013).

29. IPCC, Intergovernmental Panel on Climate Change. Volume 4 agriculture, forestry and other land use. In: Eggleston HS, Buendia L, Miwa K, Ngara T, Tanabe K (eds) 2006 IPCC Guidelines for National Greenhouse Gas Inventories. Institute for Global Environmental Strategies, Japan (2006).

30. Wettstein, S., Scharfy, D., Berli, C., Blottnitz, V. \& Stucki, M. South African maize production: mitigating environmental impacts through solar powered irrigation. Proceedings of 10th International conference on Life Cycle Assessment of Food, Dublin. (2016).

31. Goedkoop, M. et al. ReCiPe 2008, A life cycle impact assessment method which comprises harmonized category indicators at the midpoint and endpoint level, first edition Report I: characterization, first edition, 6 January 2009, Available online at https://www. pre- sustainability.com. Accessed 15 Nov 2018 (2009).

\section{Acknowledgements}

This research study was supported by the Graduate School, Chiang Mai University; Center of Excellence in Energy, Economics, and Ecological Management (3E) and Researchers for Industries (RRI) by the Thailand Research Fund (TRF).

\section{Author contributions}

Contribution to devising the concept and assumptions of the Article. Titaporn Supasri, Norihiro Itsubo and Sate Sampattagul. Contribution to devising the research methodology used. Titaporn Supasri, Norihiro Itsubo and Sate Sampattagul. Contribution to conducting empirical research, analyzing the data and making calculations. Titaporn Supasri, Norihiro Itsubo, Shabbir H. Gheewala and Sate Sampattagul. Discussion the results and contributed to the final manuscript. All authors.

\section{Competing interests}

I declare that the authors have no competing interests as defined by Nature Research, or other interests that might be perceived to influence the results and/or discussion reported in this paper.

\section{Additional information}

Correspondence and requests for materials should be addressed to S.S.

Reprints and permissions information is available at www.nature.com/reprints.

Publisher's note Springer Nature remains neutral with regard to jurisdictional claims in published maps and institutional affiliations.

(c) (i) Open Access This article is licensed under a Creative Commons Attribution 4.0 International License, which permits use, sharing, adaptation, distribution and reproduction in any medium or format, as long as you give appropriate credit to the original author(s) and the source, provide a link to the Creative Commons license, and indicate if changes were made. The images or other third party material in this article are included in the article's Creative Commons license, unless indicated otherwise in a credit line to the material. If material is not included in the article's Creative Commons license and your intended use is not permitted by statutory regulation or exceeds the permitted use, you will need to obtain permission directly from the copyright holder. To view a copy of this license, visit http://creativecommons.org/licenses/by/4.0/.

(C) The Author(s) 2020, corrected publication 2021 